\title{
Change Trajectory of Mothers' Value of Children in Infancy on Mothers' Parenting Behavior in Childhood and Children's Behavioral Problems
}

\author{
Hyun Soo Jung ${ }^{1}$, Jin Suk Lee ${ }^{2}$ \\ Master, Department of Child and Family Studies, Jeonbuk National University, Jeonju, Korea ${ }^{1}$ \\ Professor, Department of Child Studies, Jeonbuk National University, Jeonju, Korea ${ }^{2}$ \\ 영아기 어머니의 자녀가치의 변화궤적이 유아기 어머니의 양육행동과 유아의 \\ 문제행동에 미치는 영향 \\ 정현수 ${ }^{1}$, 이진숙 ${ }^{2}$ \\ 전북대학교 아동가족학과 석사 ${ }^{1}$, 전북대학교 아동학과 교수 ${ }^{2}$
}

Objectives: This study aims to provide a longitudinal analysis on the structural relationship for the change trajectory of mothers' value of children in infancy and how this value affects the mother's parenting behavior and subsequent behavioral problems of the child.

Methods: This study employed longitudinal survey data from the $1^{\text {st }}(2008) \sim 3^{\text {rd }}(2010)$ and the $6^{\text {th }}$ (2013) surveys conducted by the Panel Study on Korean Children (PSKC). The subjects of this study included 1,601 children and their mothers.

Results: Mothers' value of children in infancy demonstrated a statistically significant difference between the initial value and the rate of change in both emotional value and instrumental value, both showing a decrease over time. A significant difference was also observed in mothers' parenting behavior and their effect on the children's behavioral problems. The higher the initial emotional value, the warmer and more controlling the parenting behavior. In addition, larger rates of change led to parenting behavior with lower levels of warmth and control. Additionally, mothers' emotional value of children was shown to partially mediate the mothers' parenting behavior and the resulting behavioral problems in children. The higher the initial instrumental value, the warmer and more controlling the parenting behavior. However, the rate of change for the instrumental value did not affect mothers' parenting behavior in childhood nor the behavioral problems of the children.

Conclusion: This study confirms mothers' value of children in infancy changes over time. In addition, it also confirms that mothers' value of children is an important mechanism that influences children's behavioral problems by mediating parenting behavior; this occurs through the structural relationship in which mothers' value of children in infancy affects mothers' parenting behavior in childhood and the subsequent behavioral problems of the children.

Keywords: mother's value of children, mother's parenting behavior, childhood behavioral problems

Corresponding Author: Jin Suk Lee, Professor, Department of Child Studies, Jeonbuk National University, 567, Baekje-daero, Deokjin-gu, Jeonju, Korea, 54896

E-mail: jslee0820@jbnu.ac.kr
(C)The Korean Association of Child Studies

This is an Open Access article distributed under the terms of the Creative Commons Attribution Non-Commercial License (http:// creativecommons.org/licenses/by-nc/4.0) which permits unrestricted noncommercial use, distribution, and reproduction in any medium, provided the original work is properly cited. 


\section{Introduction}

유아기의 사회정서발달은 부모와의 관계를 시작으로 발달하 며 이후 또래와 교사와의 관계를 비롯한 대인관계에 영향을 미치기 때문에 중요한 발달 과업 중 하나이다. 사회정서발달 이 적절히 이루어지지 않으면, 대인관계에서 갈등과 좌절을 경험하게 되며 이로 인해 사회 부적응과 문제행동을 야기할 수 있다. 유아의 문제행동은 시간이 지나면서 조절능력이 발 달하고 사회기술을 습득하면서 자연스럽게 해결되기도 하지 만 적절한 개입이 없을 경우 청소년기나 성인기에 이르러 여 러 가지 심리, 정서 문제나 문제행동이 나타날 수 있다.

최근 $\mathrm{ADHD}$ 등 다양한 심리적 어려움을 겪는 아동의 수가 급증하면서 유아의 문제행동에 영향을 미치는 선행 변인을 찾 는 연구가 활발해지고 있다. 문제행동에 대한 연구 동향(S.-J. Lee \& Yoo, 2012)에서 환경 변인으로는 부모의 양육태도와 양 육행동에 대한 연구가 활발하게 진행되었다고 보고되었다. 이 는 유아의 문제행동을 예방하고 최소화하기 위해 양육행동을 가장 우선으로 고려해야하는 변인임을 의미한다. 국내 선행 연구에서는 어머니의 온정적 양육행동이 낮고 통제적 양육행 동이 높을수록 유아의 내재화 및 외현화 문제행동이 높게 나 타난다고 꾸준하게 보고되었다(Kang \& Oh, 2011; M.-E. Kim, 2016). 뿐만 아니라 국외 선행연구들에 의하면 부모가 강압적 이고 처벌적인 양육행동이 많을수록 유아의 문제행동이 증가 하는 것으로 보고하였다(Leve, Kim, \& Pears, 2005; Yoon et al., 2017). 이처럼 부모의 양육행동은 유아의 문제행동에 영향을 주는 환경 변인으로 관심이 높으며, 부모의 양육행동이 유아 의 문제행동에 영향을 미친다는 보고가 이어지고 있다.

한편, 부모의 양육행동에 영향을 미치는 변인으로 부모가 지닌 자녀에 대한 가치(이하 자녀가치)에 대한 관심이 증가하 고 있다. 자녀가치(the value of child)란, 부모가 자녀를 바라보 는 관점으로 자녀를 출산하고 양육하면서 생기는 이득과 손 실을 의미한다. 이는 자녀를 통해 얻는 경제적 가치와 자녀 로 인해 얻는 기쁨과 애정, 양육으로 인한 스트레스 등을 포 함한다. 초기 자녀가치에 대한 연구는 개인의 출산 동기나 출 산 경향과 관련된 연구를 주로 다루었다. 그러나 Okagaki와 Sternberg (1993)는 자녀가치가 자녀의 양육행동을 이끌면서 자녀와의 상호작용을 통해 자녀의 경험들을 구조화시키는 시 작점으로 보고하는 등 자녀가치가 양육행동 및 자녀 발달과 관련된 연구로 관심이 옮겨지고 있다. 국내 선행연구에 따르 면, Ok (2018)의 연구에서는 자녀에 대한 정서적 가치와 도구 적 가치가 높을수록 온정적인 양육행동을 더 많이 한다고 보
고되었고, 부모의 정서적 자녀가치가 높을수록 온정적 양육행 동이 많이 나타나고, 도구적 가치가 높을수록 통제적 양육행 동을 많이 하는 것으로 보고되었다(J. A. Lee, Park, Chung, \& Yi, 2017; Shin, 2016). 국외 선행연구에서는 부모의 양육 신념 이 양육 방식을 선택하는 것에 심리적으로 중재한다고 보고 하였고(Chan, Bowes, \& Wyver, 2009), 부모가 자녀에게 바라는 목표나 욕구가 양육 행동에 영향을 미치고 있다고 보고하였다 (Judith, 2017). 이는 부모의 자녀가치에 따라 자녀에게 기대하 는 바가 양육의 기준이 되어 자녀를 양육하는 과정에서 보다 적극적인 양육행동으로 표현되는 것으로 예측할 수 있다. 이에 자녀가치는 양육행동에 선행되며, 양육행동과 함께 유아의 문 제행동을 예측함에 있어 고려해야할 변인으로 예측할 수 있다.

또한, 부모의 자녀가치는 자녀의 발달과 적응에도 영향을 미치는 것으로 나타났다. 구체적으로 Park (2012)은 영아기 어 머니의 자녀가치가 높게 평가될수록 영아의 사회 - 정서발달 에 긍정적인 영향을 미친다고 보고하였다. 자녀가치가 유아의 발달에 미치는 영향을 살펴보면, 어머니의 자녀가치는 긍정적 또래상호작용에 강한 정적 영향력을 미치고, 부정적 또래상 호작용에는 약한 부적 영향력을 미치는 것으로 나타났다 $(\mathrm{H}$. $\operatorname{Lim} \&$ Choi, 2015). 이처럼 부모의 자녀가치는 영아기와 유아 기의 자녀발달에 영향을 주는 선행요인으로 예측할 수 있다. 그러나 자녀가 영아기일 때 가진 어머니의 자녀가치가 이후 자녀의 유아기에 미치는 영향에 대한 종단연구는 부족한 실정 이다. 이에 본 연구는 영아기 자녀가치의 변화가 이후 유아기 부모의 양육행동 및 유아의 문제행동에 미치는 영향에 초점을 맞추고자 한다.

자녀가치는 1970 년대 초부터 사용되었으며, 자녀를 통해 얻는 경제적인 가치와 사회적 의미를 찾는 도구적 가치와 자 녀로 인해 얻는 기쁨과 애정, 양육으로 인한 스트레스들을 포 함한 정서·심리적 가치로 구분된다. 정서적, 도구적 가치를 포 함한 부모의 자녀가치는 사회문화나 시대의 흐름에 따라 변화 될 수 있다. 이에 국가 간의 비교나 세대 간의 차이에 대한 연 구들이 보고되었다. 예를 들면, 농업사회였던 과거에 비해 현 대사회에서는 정서적 가치보다 도구적 가치를 점점 낮게 인식 한다고 보고하였다(Arnold \& Fawcett, 1986; Kwon, 2003). 이러 한 변화는 현대 사회에서 도구적 가치보다 정서적 가치를 높 게 평가한다는 결과로 볼 수 있다. 이는 농업사회였던 전통 사 회에서는 자녀를 가계를 계승하고 노동력을 제공하는 것에 가 치를 두었으나 현대 사회에서는 자녀를 통해 심리적 만족을 얻고 부모가 되는 일에 가치를 두는 등의 의미를 강조하고 있 다. 더불어, 최근 영아기 부모의 자녀가치의 변화궤적에 대한 
종단연구인 J. Lee, Kim과 Lee (2015)의 연구에서 자녀의 출생 부터 3세가 되는 동안 정서적 가치와 도구적 가치가 짧은 시기 에도 변화한 것으로 보고하였다. 그러나 영아기 부모의 자녀 가치가 변화하는 것을 보고하는 한 편만 있을 뿐이다. 이에 부 모가 가진 자녀가치는 사회 문화나 시간의 흐름에 따라 변화 할 것으로 예상할 수 있으며 이후 자녀를 양육하는 과정에서 미치는 영향을 밝힐 필요가 있다.

이상의 내용을 통해, 영아기 어머니의 정서적, 도구적 자녀 가치는 이후 유아기 어머니의 양육행동에 영향을 미치며, 양 육행동은 유아의 문제행동에 영향을 미칠 수 있을 것으로 예 상된다. 그러나 부모의 자녀가치와 자녀의 사회정서 발달 간 의 관련성에 대한 연구에 비해 자녀가치와 문제행동 간의 연 구는 상대적으로 소수인 상황이다. 또한 자녀가치와 양육행 동, 문제행동 간의 단기 종단 자료를 분석한 연구(S. A. Lim \& $\mathrm{Lim}, 2015)$ 만 이루어졌을 뿐이다. 더불어, 부모의 자녀가치가 시간의 흐름에 따라 변화한다는 선행연구(Kwon, 2003; J. Lee et al., 2015)를 미루어 볼 때 자녀가치가 실제 자녀를 양육하면 서 변화될 수 있을 뿐만 아니라 양육행동 및 자녀의 문제행동 에 영향을 미칠 것으로 예측할 수 있다. 이에 영아기 어머니의 자녀가치가 시간의 흐름에 따라 변화하며 이후 유아기 양육행 동과 유아의 발달과 문제행동에 미치는 영향을 종단적으로 살 펴볼 필요가 제기된다.

어머니의 자녀가치가 문제행동에 미치는 영향에 대한 종단 연구는 미흡한 상황이며, 자녀가치와 양육행동, 유아의 문제 행동 간의 구조적 관계를 살펴본 연구는 찾아보기 어렵다. 따 라서 본 연구는 어머니의 정서적, 도구적 자녀가치의 변화궤 적을 살펴보고, 자녀가치의 변화궤적과 어머니의 양육행동, 유아의 문제행동 간의 구조적 관계를 분석하는데 목적이 있 다. 이러한 연구를 통해 유아의 문제행동에 미치는 어머니의 가치 및 양육행동의 영향을 밝히고, 부모교육을 위한 기초 자 료를 제공할 수 있을 것이다. 본 연구목적에 따른 연구문제는 다음과 같다.

\section{연구문제 1}

어머니의 자녀가치(정서적, 도구적)의 변화궤적은 어떠한가?

\section{연구문제 2}

어머니의 자녀가치(정서적, 도구적)의 변화궤적이 유아의 문 제행동에 영향을 미치는 구조적 관계는 어떠한가?

\section{Methods}

\section{연구대상}

본 연구는 육아정책연구소 한국아동패널(Panel Study on Korean Children [PKSC])을 사용하였다. 한국아동패널은 2008년에 출생한 신생아 가구를 모집단으로 2,150 가구를 전체 표본으 로 구축하였다. 본 연구는 6차년도(2013년)까지 유지된 1,662 명 중 1차년도(2008년)부터 3차년도(2010년)에 조사한 어머 니의 자녀가치에 2년 이상 응답하고, 6차년도(2013년)에 조사 한 어머니의 양육행동과 유아의 문제행동에 응답한 자료를 분 석에 사용하였으며 최종 분석 대상은 1,601 명이다. 유아의 성 별은 남아가 825 명(51.5\%), 여아가 776명(48.5\%)으로 남녀아 의 비율이 거의 동일한 것으로 나타났다. 생명연구윤리위원회 (IRB) 승인 면제를 받아 분석을 실시하였다.

\section{연구도구}

\section{어머니의 자녀가치}

어머니의 자녀가치를 측정하기 위해 Lee 등(2005)의 자녀가치 척도를 육아정책연구소에서 수정한 척도를 사용하였다. 본 척 도는 자녀가치를 정서적 가치와 도구적 가치로 나누어 측정 하였다. 정서적 가치는 "부모가 되는 것은 인생에서 가치 있 는 일이다.”, "자녀가 있는 사람들은 노년에 덜 외롭다.”와 같 은 부모됨에 대한 의미를 포함하여 외로움 등의 정서적인 내 용을 묻는 3문항으로 구성되었다. 도구적 가치는 "자녀가 있 으면 노후에 경제적으로 도움을 받을 수 있다.”, “집안의 대를 잇기 위해 자녀를 두는 것은 당연하다.”와 같이 경제적인 부분 과 가계 계승, 사회적 의무를 묻는 4 문항으로 구성되어 총 7 문 항이다. 점수가 높을수록 정서적 가치, 도구적 가치가 높은 것 을 의미한다. 이 척도는 5점 Likert 척도로 측정되며 본 연구에 서 산출한 신뢰도는 정서적 가치는 .60 .69이고, 도구적 가치 는 .71 .73로 나타났다. 정서적 자녀가치의 신뢰도가 낮은 편 이나.60이상이면 내적일치도로서 적당하다는 견해가 있어 분 석에 무리가 없을 것으로 판단하였다(Bae, 2011).

\section{어머니의 양육행동}

어머니의 양육행동을 측정하기 위해 Cho, Lee, Lee와 Kwon (1999)의 양육행동 척도를 육아정책연구소에서 수정한 척도 
Table 1

Composition of Question by Sub-Factor of the Problem Behavior Scale

\begin{tabular}{llc}
\hline \multicolumn{1}{c}{ Sub-factor } & & Total number of questions \\
\hline Internalizing behavior problem & Emotionally reactive & 9 \\
& Anxious/depressed & 8 \\
& Somatic complaints & 31 \\
\hline Externalizing behavior problem & Withdrawn & 36 \\
& Attention problems & 5 \\
\hline
\end{tabular}

를 사용하였다. 자녀에 대한 애정과 관심, 자녀와의 의사소통, 양육의 즐거움 등으로 구성된 온정요인과 자녀에게 행동표준 을 설정하고 잘못된 행동을 통제하는 통제 요인으로 나누었 다. "아이의 의견을 존중하고 표현할 수 있게 한다.", "아이의 행동이나 아이가 성취한 일에 관심을 갖고 있음을 보인다."와 같은 온정적 양육 6 문항과 “나는 아이가 어려도 엄격하게 예 절을 가르친다.", "나는 아이가 짜증내는 것을 받아주지 않는 다."와 같은 통제적 문항 6 문항으로 구성되어 총 12 문항이다. 이 척도는 5점 Likert 척도로 측정되었다. 본 연구에서 산출한 신뢰도는 .80으로 나타났다. 구조방정식 분석을 위하여 온정 적 양육과 통제적 양육 모두 2문항씩 항목묶음을 실시하여 각 각 3 개의 측정변인으로 수정하여 사용하였다.

\section{유아의 문제행동}

유아의 문제행동을 측정하기 위해 표준화된 유아행동평가척 도(CBCL 1.5-5)를 사용하였다. '내재화 문제행동'은 정서적 반 응성(9문항), 불안/우울(8문항), 신체증상(11문항), 위축(8문 항)으로 총 36 문항으로 구성되어 소극적이고 위축된 행동, 정 서불안, 신체증상 등 내재화되고 지나치게 통제된 행동을 측 정하고, '외현화 문제행동'은 주의집중(5문항), 공격행동(19문 항)으로 총 24 문항으로 구성되어 주의력 문제, 공격적인 행동 등 통제가 부족한 행동을 측정한다. 이 척도는 전혀 해당되지 않는다(0점), 가끔 그렇거나 그런 편이다(1점), 자주 그런 일이 있거나 많이 그렇다(2점)의 범위에서 응답하도록 구성되었으 며, 각 항목의 합산 점수를 토대로 정도를 평가하여 점수가 높 을수록 각 항목의 문제가 높은 것을 의미한다. 한국아동패널 에서 응답지를 토대로 매뉴얼에 의거해 계산한 값을 제공하였 고, 제공한 문제행동척도의 총점, 백분위, $\mathrm{T}$ 점수 중 $\mathrm{T}$ 점수를 본 연구에서 사용하였다. 문제행동 척도의 하위요인별 문항 구성은 Table 1 에 제시하였다.

\section{자료분석}

수집된 자료는 SPSS 24.0 (IBM Co., Armonk, NY)을 이용하여 빈도분석과 기술통계, 신뢰도 분석, 상관관계 분석을 실시하 였고, AMOS 18.0 (IBM Co., Armonk, NY)을 이용하여 확인적 요인분석과 영아기 어머니의 자녀가치의 변화궤적을 확인하 기 위해 잠재성장 분석을 실시하였다. 어머니의 자녀가치의 변화궤적이 어머니의 양육행동과 유아의 문제행동에 영향을 미치는지 알아보기 위해 종단적 구조모형을 설정하여 분석하 였고, 구조적 관계에서 양육행동의 매개효과를 확인하기 위해 구조모형을 설정하여 부트스트래핑(bootstrapping)을 실시하 였다.

종단연구의 특성상 발생하게 되는 결측치는 완전정보최대 우도법(Full Information Maximum Likelihood [FIML])과 기대최대화(Expectation-Maximization [EM])를 사용하였다. 모형의 적합도는 NFI, TLI와 CFI는 .90 이상이면 적합하다고 볼 수 있 고, RMSEA는 .10 이하는 보통, .08 이하는 괜찮음, .05 이하는 좋은 적합도로 볼 수 있다(Bae, 2011). 그러나 완전정보최대우 도법은 부트스트래핑에 제약이 있어, 기대-최대화를 사용하 여 결측치를 처리한 후 부트스트래핑 검증을 하였다.

\section{Results}

\section{측정 변인의 기술통계 및 상관관계}

주요 변인들의 기초통계 분석은 Table 2에 제시하였다. 구조방 정식 모형을 실시하기 위해 분석 자료의 왜도와 첨도를 확인 하여 정규분포성의 가정이 충족되는 지 확인한 결과, 왜도는 -.95 에서 . 30 이었고, 첨도는 -.36에서 1.10 사이로 확인되었다. 왜도는 절대값 3 , 첨도는 절대값 10 을 넘지 않아 정규분포에 
Table 2

Means, Standard Deviation, Skewness and Kurtosis of the Research Variables

\begin{tabular}{|c|c|c|c|c|}
\hline Variables & & $M(S D)$ & Skewness & Kurtosis \\
\hline \multirow[t]{3}{*}{ Mother's EVC } & Wave 1 (2008) & $4.48(.52)$ & -.95 & .57 \\
\hline & Wave 2 (2009) & $4.32(.59)$ & -.87 & 1.10 \\
\hline & Wave 3 (2010) & $4.29(.57)$ & -.65 & .46 \\
\hline \multirow[t]{3}{*}{ Mother's IVC } & Wave 1 (2008) & $2.96(.77)$ & .01 & -.29 \\
\hline & Wave 2 (2009) & $2.92(.77)$ & .12 & -.07 \\
\hline & Wave 3 (2010) & $2.90(.75)$ & .09 & -.09 \\
\hline Mother's WPB & Wave 6 (2013) & $3.68(.55)$ & -.06 & .19 \\
\hline Mother's CPB & & $3.49(.51)$ & -.07 & .15 \\
\hline Children's IBP & Wave 6 (2013) & $48.21(9.88)$ & .30 & .09 \\
\hline Children's EBP & & $47.09(9.57)$ & .21 & -.36 \\
\hline
\end{tabular}

Note. $N=1,601 . \mathrm{EVC}=$ Emotional value of children; $\mathrm{IVC}=$ Instrumental value of children; WPB = Warm parenting behavior; $\mathrm{CPB}=$ Controlled parenting behavior; IBP = Internalizing behavioral problems; EBP = Externalizing behavioral problems.

Table 3

Correlation of Mother's Value of Children, Parenting Behavior, and Childhood Behavioral Problems

\begin{tabular}{|c|c|c|c|c|c|c|c|c|c|c|}
\hline & $\begin{array}{l}\text { 1. EVC } \\
(2008)\end{array}$ & $\begin{array}{l}\text { 2. EVC } \\
(2009)\end{array}$ & $\begin{array}{l}\text { 3. EVC } \\
(2010)\end{array}$ & $\begin{array}{l}\text { 4. IVC } \\
(2008)\end{array}$ & $\begin{array}{l}\text { 5. IVC } \\
(2009)\end{array}$ & $\begin{array}{l}\text { 6. IVC } \\
(2010)\end{array}$ & $\begin{array}{l}\text { 7. WPB } \\
(2013)\end{array}$ & $\begin{array}{l}\text { 8. CPB } \\
(2013)\end{array}$ & $\begin{array}{l}\text { 9. IBP } \\
(2013)\end{array}$ & $\begin{array}{c}\text { 10. EBP } \\
(2013)\end{array}$ \\
\hline 1. & - & & & & & & & & & \\
\hline 3. & $.38^{* * *}$ & $.52^{* * *}$ & - & & & & & & & \\
\hline 4. & $.37^{* * *}$ & $.23^{* * *}$ & $.24^{* * *}$ & - & & & & & & \\
\hline 6. & $.22^{* * *}$ & $.25^{* * *}$ & $.41^{* * *}$ & $.55^{* * *}$ & $.62^{* * *}$ & - & & & & \\
\hline 7. & $.15^{* * *}$ & $.18^{* * *}$ & $.17^{* * *}$ & $.08^{* *}$ & $.10^{* * *}$ & $.08^{* *}$ & - & & & \\
\hline 8. & .03 & $.06^{*}$ & .05 & .05 & $.09^{* *}$ & $.09^{* * *}$ & $.21^{* * *}$ & - & & \\
\hline 9. & $-.07^{* *}$ & $-.09^{* * *}$ & $-.12^{* * *}$ & $-.12^{* * *}$ & $-.11^{* * *}$ & $-.10^{* * *}$ & $-.20^{* * *}$ & .02 & - & \\
\hline 10. & $-.09^{* * *}$ & $-.11^{* * *}$ & $-.13^{* * *}$ & $-.12^{* * *}$ & $-.10^{* * *}$ & $-.07^{* *}$ & $-.28^{* * *}$ & .02 & $.73^{* * *}$ & - \\
\hline
\end{tabular}

Note. $N=1,601$.

${ }^{*} p<.05 .{ }^{* *} p<.01 .{ }^{* * *} p<.001$.

서 벗어나지 않음을 확인하였다. 본 연구에서 사용한 분석 자 료는 정규분포의 조건을 충족시켜 구조방정식 모형 적용이 가 능함을 확인하였다.

어머니의 자녀가치와 양육행동, 유아의 문제행동 간의 상 관관계를 살펴보기 위하여 Pearson 상관 분석을 실시하였으며 결과는 Table 3 과 같다. 어머니의 정서적 자녀가치는 온정적 양육행동과 정적 상관을 보이고, 통제적 양육행동과는 유의미 하지 않았다. 도구적 자녀가치는 온정적 양육행동과 약한 정 적 상관을 보였고, 통제적 양육행동과 정적상관을 나타났다. 어머니의 온정적 양육행동은 유아의 내재화 문제행동과 외현 화 문제행동 모두 부적 상관을 보였고, 통제적 양육행동은 유
의미한 결과가 나타나지 않았다. 어머니의 자녀가치와 유아의 문제행동 간의 관계를 살펴보면, 정서적 자녀가치는 내재화 문제행동과 외현화 문제행동 모두 부적 상관을 보였고, 도구 적 자녀가치 또한 내재화 문제행동과 외현화 문제행동에 부적 상관을 보였다.

\section{어머니의 자녀가치의 변화궤적 추정}

영아기 어머니의 자녀가치의 변화 양상을 살펴보기 위해 Figure 1 과 같이 무변화 모형과 선형모형을 비교하였으며, 정서 적 자녀가치와 도구적 자녀가치를 각각 나누어 분석하였다. 


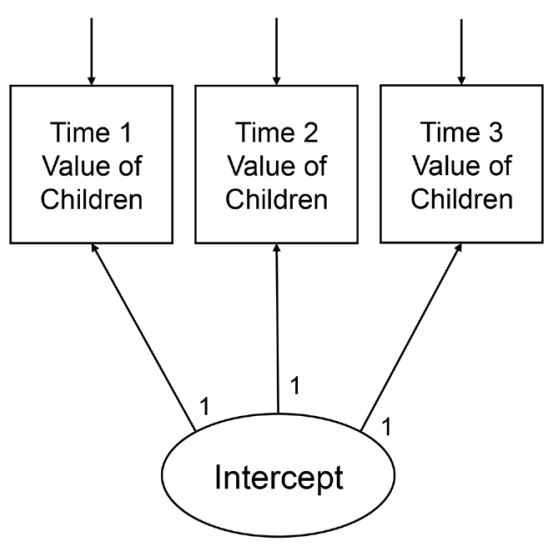

Model 1 : No Change Model

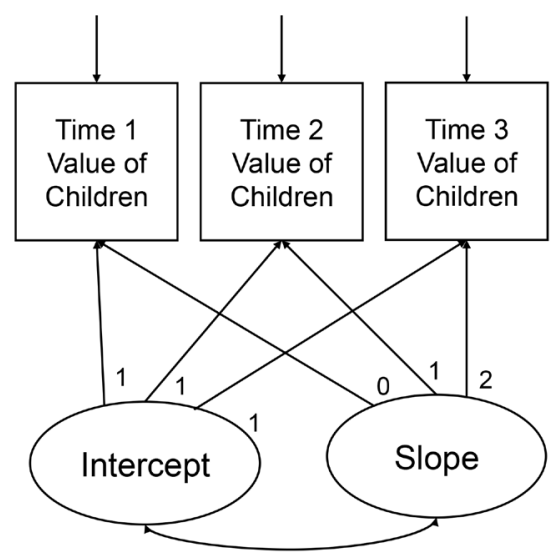

Model 2 : Liner Model

Figure 1. Latent growth model of the value of children.

Table 4

Latent Growth Model Fit by the Type of Change Model

\begin{tabular}{llrrrrr}
\hline \multicolumn{1}{c}{ Variables } & \multicolumn{1}{c}{ Type of change model } & $\chi^{2}(d f)$ & NFI & TLI & CFI & RMSEA \\
\hline Mother's emotional value of children & No change model & $215.44(4)$ & .75 & .62 & .75 & .18 \\
& Linear model & $25.32(1)$ & .97 & .83 & .97 & .10 \\
\hline Mother's instrumental value of children & No change model & $27.35(4)$ & .98 & .98 & .99 & .06 \\
& Linear model & $.13(1)$ & 1.00 & 1.00 & 1.00 & .00 \\
\hline
\end{tabular}

Table 5

Mean and Variances of Intercept and Slope

\begin{tabular}{lccccc}
\hline \multicolumn{1}{c}{ Variables } & Intercept mean & Intercept variance & Slope mean & Slope variance & $\mathrm{I} \leftrightarrow$ S covariance \\
\hline Emotional & $4.55^{* * *}$ & $-.09^{* * *}$ & $.22^{* * *}$ & $.04^{* * *}$ & $-.05^{* * *}$ \\
Instrumental & $3.00^{* * *}$ & $-.03^{* * *}$ & $.58^{* * *}$ & $.04^{* * *}$ & $-.10^{* * *}$ \\
\hline
\end{tabular}

${ }^{* * *} p<.001$.

Table 4에 제시한 분석 결과를 살펴보면, 영아기 어머니의 정 서적 자녀가치가 변화하지 않는다고 가정한 모형과 선형으로 변화한다는 가정의 모형간의 $\chi^{2}$ 및 자유도의 차이는 $190.12,3$ 으로 임계치인 7.81보다 크기 때문에 영가설을 기각한다. 이 에 두 모형은 유의하게 다르며, 선형모형이 선택되었다. 도구 적 자녀가치의 경우 무변화 모형과 선형모형간의 $\chi^{2}$ 및 자유 도의 차이는 $27.22,3$ 으로 임계치인 7.81보다 커서 영가설을 기각한다. 따라서 두 모형은 유의하게 다르며, 선형모형이 자 녀가치의 변화패턴을 보다 잘 설명하여 선형모형이 선택되었 다. 모형의 적합도를 살펴보면 정서적 자녀가치의 경우 TLI값 이 .90보다 작으나 NFI, CFI 값이 .90이상이고, RMSEA 값이 .10 이하로 권장 수용수준 이상으로 분석에 무리가 없을 것으 로 판단하였다.
Table 5에 제시된 정서적 자녀가치의 초기값 평균은 4.55 $(p<.001)$ 이고 변화율 평균은 -.09 ( $p<.001)$ 로 영아기 동안 해마다. 09씩 감소하였다. 초기값의 분산은 $.22(p<.001)$ 이고 변화율의 분산은 .04 $(p<.001)$ 로 어머니의 정서적 자녀가치 의 변화 궤적은 유의한 개인차가 있으며, 초기값과 변화율 사 이의 공분산이 -.05 ( $p$ <.001)로 음수로 나타나 시작점에서 정 서적 자녀가치를 높게 인식한 어머니는 정서적 자녀가치가 완 만하게 감소하였다.

도구적 자녀가치의 초기값 평균은 $3.00(p<.001)$ 이고 변화 율 평균이 -.03 ( $p<.001)$ 로 영아기 어머니의 도구적 자녀가치 는 해마다 .03씩 감소하였다. 초기값 분산은 $.85(p<.001)$ 이 고 변화율 분산이 .04 ( $p$ < .001)로 어머니 도구적 자녀가치의 변화궤적은 유의미한 개인차를 확인하였으며, 초기값과 변화 
율 사이의 공분산이 -.10 ( $p<.001)$ 로 음수로 나타나 시작점에 서 도구적 자녀가치를 높게 인식한 어머니는 도구적 자녀가치 가 완만하게 감소하였다.

\section{어머니의 자녀가치의 변화궤적, 양육행동, 유아의 문제행동 간의 구조적 관계}

영아기 어머니의 자녀가치의 변화궤적, 유아기 어머니의 온정 및 통제적 양육행동, 유아의 문제행동 간의 구조적 관계를 파 악하기 위하 Figure 2와 같이 기저모형을 설정하고, 적합도 검 증을 통해 유아기 어머니의 자녀가치의 변화궤적이 유아기 어 머니의 양육행동을 매개로 유아의 문제행동에 유의한 영향을 미치는지 확인하였다. 기저모형의 적합도를 확인한 결과 $\chi^{2}=$ $581.66(d f=80), \mathrm{NFI}=.91, \mathrm{TLI}=.89, \mathrm{CFI}=.93, \mathrm{RMSEA}=.06$ 으로 TLI값이 .90이상이지 않지만 그 외 적합도가 양호한 수 준으로 나타나 분석에 무리가 없을 것으로 판단하여 최종 모 형으로 선택하였다.

어머니의 자녀가치를 정서적 자녀가치와 도구적 자녀가치 로 나누어 각각 분석을 실시하였다. 정서적 자녀가치의 변화 궤적이 양육행동과 유아의 문제행동에 이르는 경로에 대한 적합도 지수는 $\chi^{2}=378.78(d f=37, p<.001), \mathrm{NFI}=.94, \mathrm{TLI}=$ $.92, \mathrm{CFI}=.94, \mathrm{RMSEA}=.08$ 로 나타나 양호한 수준의 모형으 로 확인되었으며, 각 변인들 간의 구체적인 영향력은 Figure 3 에 제시하였다. 어머니의 정서적 가치의 초기값은 온정적 양 육행동 $(\beta=.30, p<.001)$ 과 통제적 양육행동 $(\beta=.11, p<.01)$ 에
통계적으로 유의미한 정적 영향력이 있다. 즉, 어머니의 정서 적 가치의 초기값이 클수록 양육행동의 온정 및 통제 수준이 높아지는 것으로, 어머니의 정서적 가치가 높을수록 온정 및 통제적 양육행동이 많아지는 것을 의미한다. 어머니의 정서적 가치의 변화율은 온정적 양육행동 $(\beta=.23, p<.001)$ 과 통제적 양육행동 $(\beta=.10, p<.01)$ 에 유의미한 정적 영향력이 있다. 이 는 어머니의 정서적 가치 변화율, 즉 어머니의 정서적 가치가 빠르게 감소할수록 온정 및 통제적 양육행동도 빠르게 감소하 고, 정서적 가치가 느리게 감소할수록 온정 및 통제적 양육행 동도 느리게 감소하는 것을 의미한다.

어머니의 정서적 가치 초기값은 유아의 문제행동에 유의 미한 부적 영향력을 보인다 $(\beta=-.10, p<.01)$. 어머니의 정서적 가치의 초기값이 클수록 유아의 문제행동이 감소하는 것으로, 어머니의 정서적 가치가 높을수록 유아의 문제행동이 발생이 낮은 것을 의미한다. 어머니의 정서적 가치의 변화율은 유아 의 문제행동에 통계적으로 유의미한 부적 영향력을 보인다 $(\beta$ $=-.11, p<.01)$. 어머니의 정서적 가치가 빠르게 감소할수록 유 아의 문제행동이 빠르게 증가하고, 정서적 가치가 느리게 감 소할수록 유아의 문제행동이 느리게 증가하는 것을 의미한다.

마지막으로 어머니의 온정적 양육행동 및 통제적 양육행동 이 유아의 문제행동에 미치는 영향을 살펴본 결과, 어머니의 온 정적 양육행동은 유아의 문제행동에 통계적으로 유의미한 부 적 영향력 $(\beta=-.29, p<.001)$ 을 가진 반면, 통제적 양육행동은 통 계적으로 유의한 영향을 미치지 않았다. 이는 어머니의 온정적 양육행동이 높을수록 유아의 문제행동이 낮은 것을 의미한다.

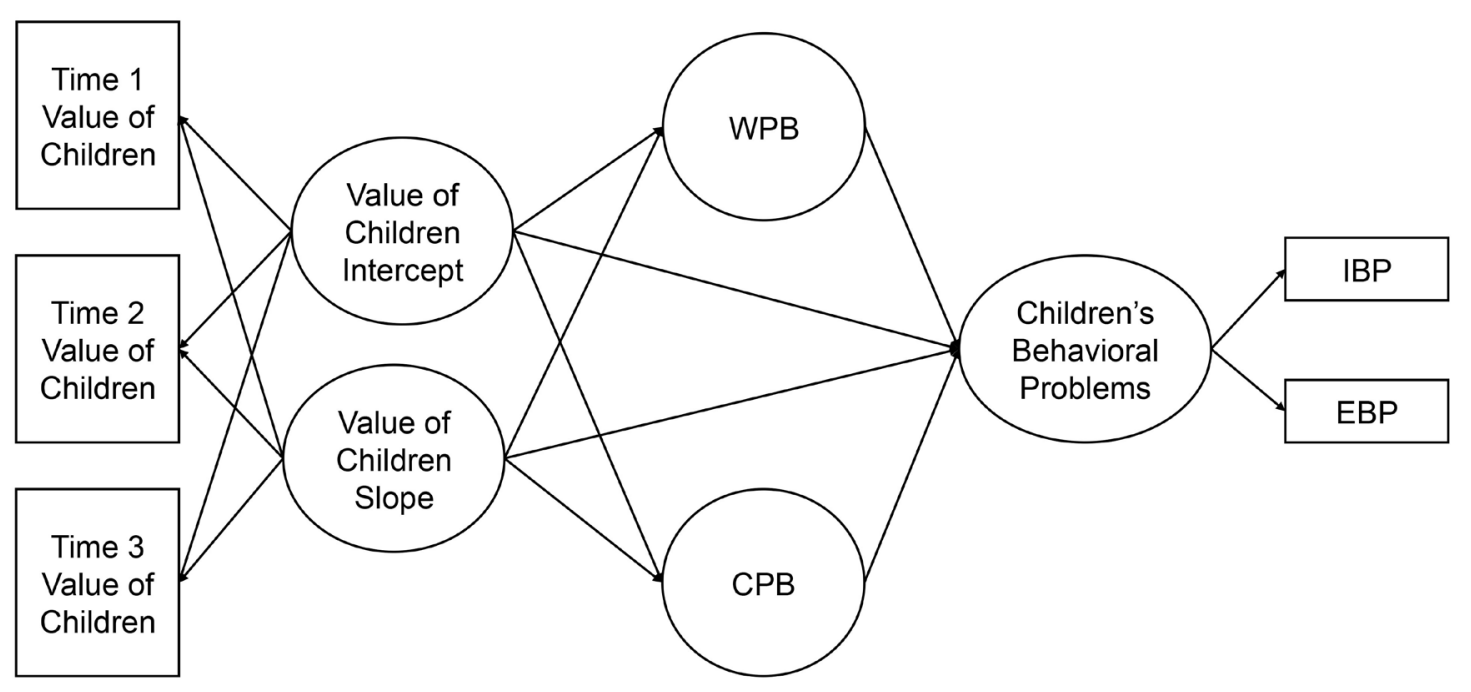

Figure 2. Hypothetical model of the trajectory of mothers' value of children, WPB, and CPB, and children's IBP and EBP. 


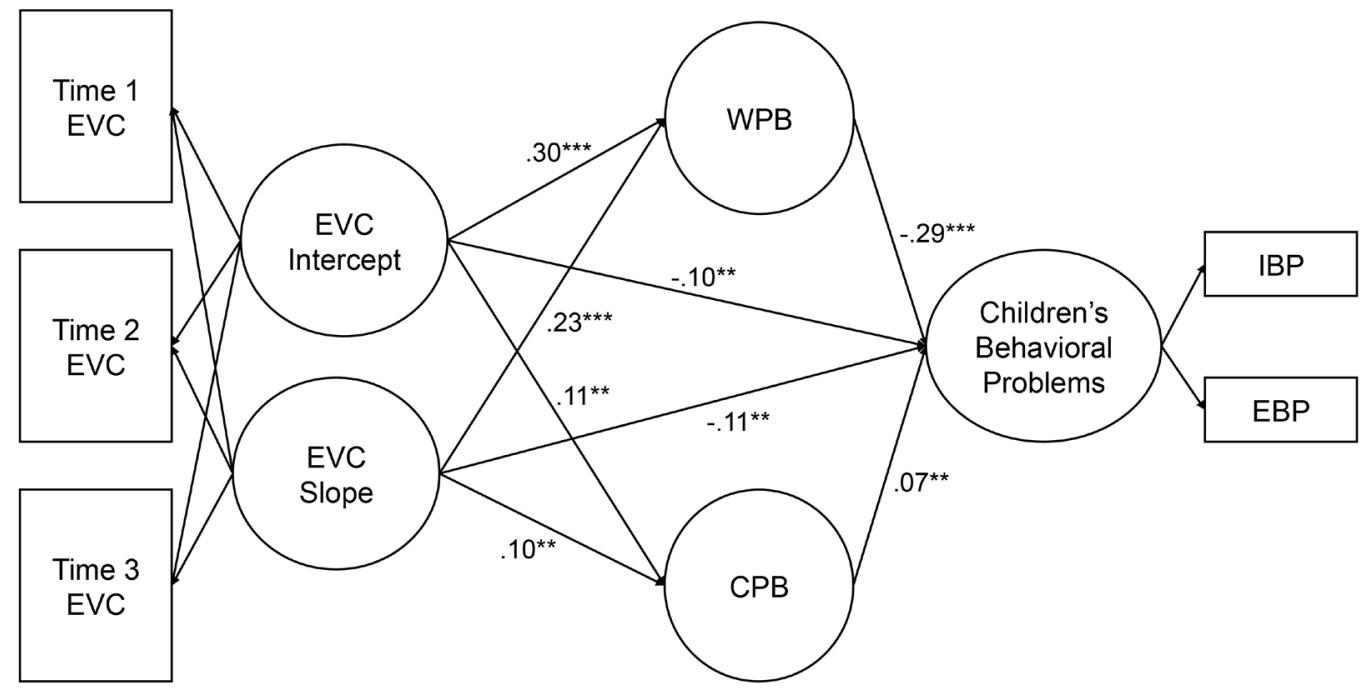

Figure 3. Hypothetical model of EVC trajectory, WPB, and CPB, and children's IBP and EBP.

${ }^{* *} p<.01 .{ }^{* * *} p<.001$.

어머니의 정서적 자녀가치와 어머니의 양육행동, 유아의 문 제행동 간의 구조적 관계에서 어머니의 양육행동의 매개효과 를 검증하기 위해 부트스트래핑(Bootstrapping)을 실시하였고, 직접효과, 간접효과, 총효과에 대한 검증 결과는 Table 6과 같 다. 유아의 문제행동에 대한 어머니의 정서적 가치 초기값의 효과분해 결과, 직접효과 $(\beta=-.10, p<.05)$ 와 간접효과 $(\beta=-.08$, $p<.01)$, 총효과 $(\beta=-.18, p<.05)$ 가 모두 통계적으로 유의하였 다. 유아의 문제행동에 대한 어머니의 정서적 가치 초기값의 간접효과는 정서적 가치 초기값 $\rightarrow$ 온정적 양육행동 $\rightarrow$ 유아 의 문제행동, 정서적 가치 초기값 $\rightarrow$ 통제적 양육행동 $\rightarrow$ 유아 의 문제행동을 포함한 것으로, 이는 어머니의 정서적 가치 초 기값과 유아의 문제행동의 관계에서 어머니의 온정적 양육행 동과 통제적 양육행동이 매개하는 것을 의미한다. 즉 어머니의 정서적 가치의 초기값이 유아의 문제행동이 미치는 직접적인 영향력이 통계적으로 유의미하였으며 온정 및 통제적 양육행 동을 매개경로로 투입함으로써 간접효과가 유의한 것으로 나 타났으므로, 온정 및 통제적 양육행동이 어머니의 정서적 가치 와 유아의 문제행동의 관계를 부분 매개한다고 볼 수 있다.

유아의 문제행동에 대한 어머니의 정서적 가치 변화율의 효과분해 결과, 직접효과 $(\beta=-.11, p<.05)$ 와 간접효과 $(\beta=-.06$, $p<.05)$, 총효과 $(\beta=-.17, p<.01)$ 가 모두 통계적으로 유의하였 다. 유아의 문제행동에 대한 어머니의 정서적 가치 변화율의 간접효과는 정서적 가치 변화율 $\rightarrow$ 온정적 양육행동 $\rightarrow$ 유아 의 문제행동, 정서적 가치 변화율 $\rightarrow$ 통제적 양육행동 $\rightarrow$ 유아 의 문제행동을 포함한 것으로, 이는 어머니의 정서적 가치 변
화율과 유아의 문제행동의 관계에서 어머니의 온정적 양육행 동과 통제적 양육행동이 매개하는 것을 의미한다. 즉 어머니의 정서적 가치의 변화율이 유아의 문제행동이 미치는 직접적인 영향력이 통계적으로 유의미하였으며 온정 및 통제적 양육행 동을 매개경로로 투입함으로써 간접효과가 유의한 것으로 나 타났으므로, 온정 및 통제적 양육행동이 어머니의 정서적 가치 와 유아의 문제행동의 관계를 부분 매개한다고 볼 수 있다.

도구적 자녀가치의 변화궤적이 양육행동과 유아의 문제행 동에 이르는 경로에 대한 적합도 지수는 $\chi^{2}=372.59(d f=37, p$ $<.001), \mathrm{NFI}=.94, \mathrm{TLI}=.93, \mathrm{CFI}=.95, \mathrm{RMSEA}=.08$ 로 나타나 양호한 수준의 모형으로 확인되었으며, 각 변인들 간의 구체 적인 영향력은 Figure 4 에 제시하였다. 어머니의 도구적 가치 의 초기값은 온정적 양육행동 $(\beta=.15, p<.001)$ 과 통제적 양육 행동 $(\beta=.16, p<.001)$ 에 정적 영향력을 보인다. 즉, 어머니의 도구적 가치의 초기값이 클수록 양육행동의 온정 및 통제 수 준이 높아지는 것으로, 어머니의 도구적 가치가 높을수록 온 정 및 통제적 양육행동이 많아지는 것을 의미한다. 어머니의 도구적 가치의 변화율은 온정적 양육행동에 통계적으로 유의 미한 영향력이 없었으나, 통제적 양육행동에 약한 정적 영향 력을 가진다 $(\beta=.18, p<.01)$. 이는 어머니의 도구적 가치가 빠 르게 감소할수록 통제적 양육행동도 빠르게 감소하고, 도구적 가치가 느리게 감소할수록 통제적 양육행동도 느리게 감소하 는 것을 의미한다.

어머니의 도구적 가치 초기값은 유아의 문제행동에 부적 영향력을 보인다 $(\beta=-.12, p<.001)$. 어머니의 도구적 가치의 
Table 6

Results of Direct, Indirect, and Total Effects in the EVC Model

\begin{tabular}{lllccc}
\hline & \multicolumn{2}{c}{ Paths } & Total effects $(\beta)$ & Direct effects $(\beta)$ & Inderect effects $(\beta)$ \\
\hline EVC intercept & $\rightarrow$ & WPB & $.30^{*}$ & - & $.30^{*}$ \\
EVC slope & $\rightarrow$ & WPB & $.23^{*}$ & $-23^{*}$ \\
EVC intercept & $\rightarrow$ & $\mathrm{CPB}$ & $.11^{*}$ & - & $.11^{*}$ \\
EVC slope & $\rightarrow$ & $\mathrm{CPB}$ & $.10^{*}$ & $-.08^{* *}$ & $.10^{*}$ \\
EVC intercept & $\rightarrow$ & Children's BP & $-.10^{*}$ & $-.06^{*}$ & $-.18^{*}$ \\
EVC slope & $\rightarrow$ & Children's BP & $-.11^{*}$ & - & $-.17^{* *}$ \\
WPB & $\rightarrow$ & Children's BP & $-.29^{* *}$ & $-.29^{* *}$ \\
$\mathrm{CPB}$ & $\rightarrow$ & Children's BP & .07 & .00 \\
\hline
\end{tabular}

Note. $N=1,601$.

${ }^{*} p<.05 .{ }^{* *} p<.01$.

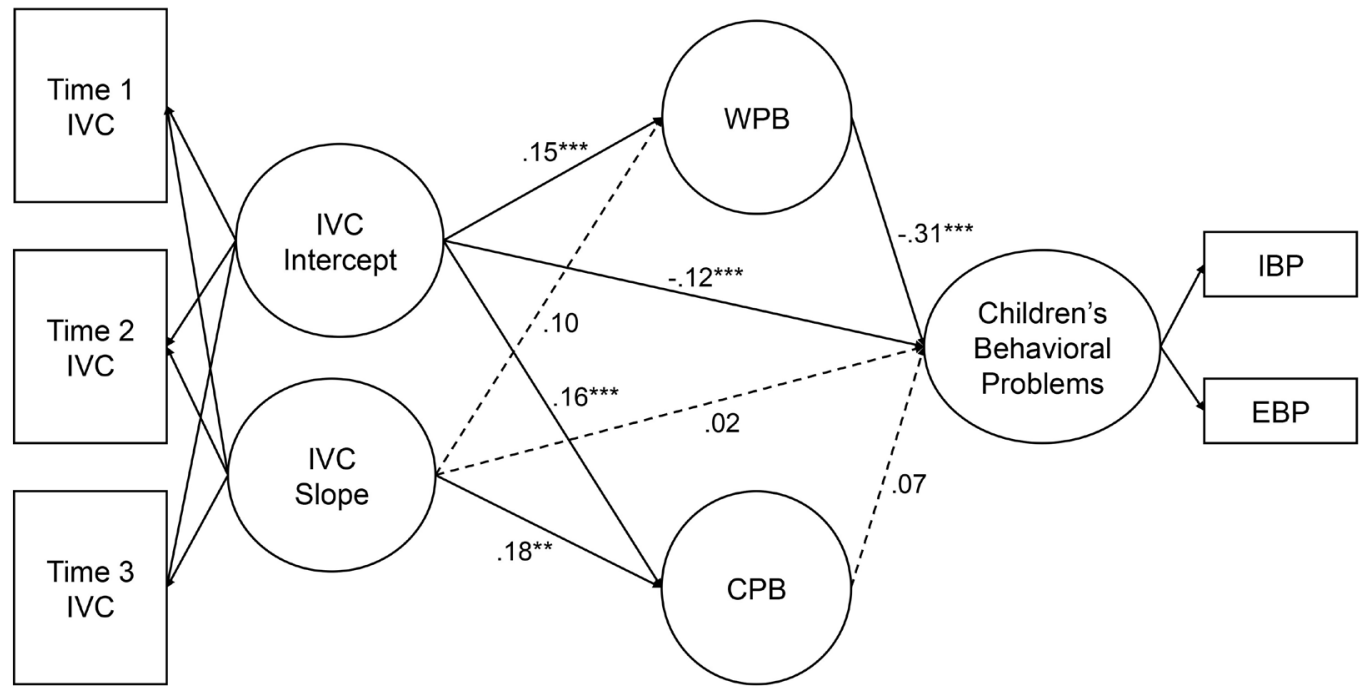

Figure 4. Hypothetical model of IVC trajectory, WPB, and CPB, and children's IBP and EBP.

${ }^{* *} p<.01 .{ }^{* * *} p<.001$.

초기값이 클수록 유아의 문제행동이 감소하는 것으로, 어머니 의 도구적 가치가 높을수록 유아의 문제행동이 발생이 낮은 것을 의미한다. 어머니의 도구적 가치의 변화율은 유아의 문 제행동에 유의미한 영향이 없다.

마지막으로 어머니의 온정적 양육행동은 유아의 문제행동 에 부적 영향력 $(\beta=-.31, p<.001)$ 을 나타낸 반면, 통제적 양육 행동의 영향력은 통계적으로 유의하지 않았다. 이는 어머니의 온정적 양육행동이 높을수록 유아의 문제행동이 낮아지는 것 을 의미한다.

어머니의 도구적 자녀가치와 어머니의 양육행동, 유아의 문제행동 간의 구조적 관계에서 어머니의 양육행동의 매개효 과를 검증하기 위해 부트스트래핑(Bootstrapping)을 실시하였 고, 직접효과, 간접효과, 총효과에 대한 검증 결과는 Table 7과
같다. 유아의 문제행동에 대한 어머니의 도구적 가치 초기값 의 효과분해 결과, 간접효과 $(\beta=-.03, p<.05)$ 으로 유의하였으 나 직접효과와 총효과는 통계적으로 유의하지 않았다. 어머니 의 도구적 가치 초기값은 유아의 문제행동에 미치는 간접효과 가 유의하고, 정서 초기값은 유아의 문제행동에 직접효과를 유 의하지 않아 온정적 양육행동과 통제적 양육행동이 어머니의 도구적 가치와 유아의 문제행동을 완전매개 하는 것으로 나타 났다. 이는 어머니의 도구적 가치 초기값이 유아의 문제행동에 직접적인 영향은 주지 않으며 온정적 양육행동과 통제적 양육 행동을 매개로 간접적인 영향을 준다는 것을 의미한다.

또한, 어머니의 도구적 가치 변화율의 직접효과와 간접효 과, 총효과가 모두 통계적으로 유의하지 않았다. 이는 어머니 의 도구적 가치 변화율은 유아의 문제행동과의 관계에서 온정 
Table 7

Results of Direct, Indirect, and Total Effects in the IVC Model

\begin{tabular}{lllccc}
\hline \multicolumn{2}{c}{ Paths } & & Total effects $(\beta)$ & Direct effects $(\beta)$ & Inderect effects $(\beta)$ \\
\hline IVC intercept & $\rightarrow$ & WPB & $.15^{*}$ & - & $.15^{*}$ \\
IVC slope & $\rightarrow$ & WPB & .10 & - & .10 \\
IVC intercept & $\rightarrow$ & $\mathrm{CPB}$ & $.16^{*}$ & - & $.16^{*}$ \\
IVC slope & $\rightarrow$ & $\mathrm{CPB}$ & $.18^{* *}$ & - & $.18^{* *}$ \\
IVC intercept & $\rightarrow$ & Children's BP & -.12 & $-.03^{*}$ & -.15 \\
IVC slope & $\rightarrow$ & Children's BP & .02 & -.02 & .00 \\
WPB & $\rightarrow$ & Children's BP & $-.31^{*}$ & - & $-.31^{*}$ \\
$\mathrm{CPB}$ & $\rightarrow$ & Children's BP & .07 & - & .07 \\
\hline
\end{tabular}

${ }^{*} p<.05 .{ }^{* *} p<.01$.

적 양육행동과 통제적 양육행동 모두 매개하지 않는 것을 의 미한다.

\section{Discussion}

본 연구의 목적은 어머니의 자녀가치의 변화궤적과 양육행동 및 유아의 문제행동에 대한 구조적 관계를 확인하고 양육행동 의 매개효과를 규명하는 것이다. 주요 결과를 요약하고 논의 하면 다음과 같다.

첫째, 어머니의 자녀가치를 정서적 자녀가치와 도구적 자 녀가치로 나누어 자녀가치의 변화궤적을 잠재성장모형을 통 해 확인해본 결과, 정서적 자녀가치의 초기값의 평균과 변화 율 평균의 유의미한 차이가 있었다. 정서적 자녀가치는 시간 에 따라 감소하였으나, 여전히 높은 편이었다. 도구적 자녀가 치는 정서적 가치에 비해 초기값이 낮았고, 변화율 역시 낮은 양상을 보였다. 이와 같은 결과는 0-3세가 되는 동안 어머니가 인식하는 정서적 자녀가치와 도구적 자녀가치가 감소하는 변 화궤적이 나타난다고 보고한 J. Lee 등(2015)의 연구와 맥락을 같이한다. 즉, 영아기 어머니의 자녀가치는 시간이 지남에 따 라 자녀를 양육하면서 느끼는 기쁨이나 행복이 감소하며, 가 계계승이나 사회적 의무에 대한 가치도 감소하는 것을 의미한 다. 이는 자녀를 출산하고 영아기 동안 자녀를 양육함에 있어 자녀를 경제적 이득을 얻는 존재로 여기기보다 정서적 만족을 주는 존재로 인식하는 경향이 크며, 이 또한 양육 과정에서의 사회적, 경제적 어려움이나 양육 스트레스를 비롯한 여러 가 지 변인들로 인해 영아기에 인식한 자녀가치가 변화한 것으로 생각할 수 있다.

둘째, 영아기 어머니의 정서적 가치의 변화궤적과 유아기
어머니의 양육행동 및 유아의 문제행동 간의 구조적 관계를 확인하기 위한 구조모형 분석을 실시하였다. 먼저, 어머니의 정서적 가치의 초기값이 높을수록 온정 및 통제적 양육행동 이 많이 나타나며, 정서적 가치의 변화율이 온정 및 통제적 양 육행동에 영향을 주는 것으로 나타났다. 이는 자녀에 대한 정 서적 가치가 높을수록 양육행동의 온정과 통제수준이 높다고 보고한 연구( J. A. Lee et al., 2017; Shin, 2016)및 온정적 양육행 동에 높다고 보고한 연구(Ok, 2018)와 유사한 결과이다. 즉 출 산 초기 어머니가 자녀양육에 대한 기쁨이나 행복 등 긍정적 인 정서가치를 높게 가질수록, 이후 유아에 대한 애정 및 통제 적 수준이 높은 양육행동을 보이는 것을 의미한다. 또한, 영아 기 어머니의 정서적 가치가 빠르게 감소할수록 이후 양육행동 의 온정 및 통제수준이 빠르게 감소한다. 이러한 결과는 시간 에 따라 변화하는 어머니의 자녀가치가 양육의 실제인 양육행 동에 직접적인 영향을 미치는 것으로 볼 수 있으며, 부모됨이 나 자녀를 통해 얻는 정서적 만족감이 높을수록 자녀의 양육 에 적극적으로 참여하며 온정과 통제 수준이 고루 높은 양육 행동을 보이는 것을 보여주는 결과이다.

다음으로, 어머니의 정서적 가치의 변화궤적이 유아의 문 제행동에 미치는 영향을 살펴보면, 정서적 가치의 초기값과 변화율 모두 통계적으로 유의미한 부적 영향력이 나타났다. 즉, 영아기 어머니의 정서적 자녀가치가 높을수록 유아의 문 제행동 수준이 낮고, 0-3세 시기의 어머니의 정서적 가치가 빠 르게 감소할수록 유아의 문제행동이 증가하는 것을 의미한다. 이는 유아기 어머니의 자녀가치가 유아의 문제행동에 직접적 인 영향을 주지 않는다는 선행연구(S. A. Lim \& Lim, 2015)와 차이가 있다. 이러한 결과는 영아기 어머니의 초기 자녀가치 가 높고 정서적 가치의 변화율이 낮을수록 온정적이고 통제적 인 양육행동이 증가하며 적극적인 양육행동이 문제행동 감소 
에 영향을 미칠 수 있음을 시사한다.

셋째, 어머니의 도구적 가치의 변화궤적과 양육행동, 유아 의 문제행동의 구조적 관계를 분석한 결과, 어머니의 도구적 가치의 초기값은 양육행동 및 문제행동에 영향을 미치는 반 면, 변화율의 경우 유의한 영향을 미치지 않는 것으로 분석되 었다. 구체적으로, 영아기 어머니의 도구적 가치의 초기값은 온정 및 통제적 양육행동에 유의한 영향을 미쳐 도구적 자녀 가치가 높을수록 온정 및 통제수준이 높은 것으로 나타났다. 또한 도구적 가치의 초기값은 유아의 문제행동에 유의한 부 적 영향이 있는 것으로 나타나 도구적 가치가 높을수록 유아 의 문제행동 수준이 낮은 것으로 나타났다. 본 연구에서는 어 머니의 도구적 자녀가치가 유아의 문제행동에 영향을 주는 것 으로 나타나 선행연구(S. A. Lim \& Lim, 2015)와 차이가 있다. 이러한 결과는 정서적 자녀가치에 비해 초기 도구적 자녀가치 수준이 낮아 유의한 영향을 미치지 않았을 것으로 생각된다. 그 이유로는 전통사회에는 가계 계승과 같은 사회적 의무나 노동력으로 평가하는 등 도구적 가치를 높게 평가하였으나 현 대 사회에는 자녀를 통해 얻는 경제적 가치보다 자녀 양육으 로 인한 경제적 부담으로 인해 도구적 가치를 낮게 평가했을 것으로 생각할 수 있다.

넷째, 어머니의 정서적 가치와 유아의 문제행동 간의 관계에 서 양육행동의 매개효과를 검증한 결과 직접효과와 간접효과, 총효과가 모두 통계적으로 유의하였다. 즉 어머니의 정서적 가 치 초기값이 온정 및 통제적 양육행동을 매개로 유아의 문제행 동에 영향을 주는 것을 확인하였다. 정서적 가치의 변화율의 효 과분해 역시 직접효과와 간접효과, 총효과가 통계적으로 유의 하여 어머니의 정서적 가치가 변화에 따라 양육행동을 부분 매 개로 문제행동에 영향을 미치는 것으로 분석되었다. 한편, 어머 니의 도구적 가치와 유아의 문제행동 간의 관계에서 양육행동 의 매개효과를 검증한 결과, 도구적 가치의 초기값은 온정적 양 육행동을 매개로 유아의 문제행동에 영향을 미치는 것으로 나 타났으나 변화율에 따른 매개효과는 나타나지 않았다.

이러한 결과는 영아기 어머니의 자녀가치가 자녀의 문제행 동에도 직접적인 영향을 미치며, 자녀를 바라보는 관점인 자 녀가치가 양육의 실제인 양육행동을 통해 자녀의 문제행동에 도 영향을 미치는 것으로 밝혀졌다. 이에 자녀의 문제행동을 감소시키기 위해 긍정적인 자녀가치를 형성하는 것이 중요하 며, 영아기의 자녀가치가 유아기 양육행동에 이르기까지 긍정 적으로 유지될 수 있도록 돕는 것이 필요하다.

본 연구를 통해볼 때, 부모가 되는 것을 가치롭게 여기고 자 녀출산이 사회적 의무를 다하는 것이라고 생각하는 등 정서적,
도구적 자녀가치를 높게 인식할수록 자녀에 대한 높은 관심과 애정을 갖는 양육행동을 갖게 된다. 이러한 양육행동은 유아의 부정적 행동발달을 예방하는데 영향을 미칠 수 있음을 시사 받 을 수 있다. 또한, 유아기 어머니의 자녀가치 변화 양상을 파악 하고, 영아기 어머니의 자녀가치가 이후 유아기 어머니의 양육 행동을 매개하여 유아의 문제행동에 미치는 종단적 영향을 알 아보는 구조적 관계를 확인했다는 것에 의미가 있다.

본 연구는 전국의 아동을 대상으로 표본조사가 된 육아정 책연구원의 아동패널조사(PSKC)를 이용함으로써 특정지역 에서 수집된 자료보다 더 높은 일반화 적용이 가능하다. 또한 어머니의 자녀가치가 변화하는 것과 영아기 자녀가치가 이후 어머니의 양육행동에 영향을 주며, 더 나아가 유아의 문제행 동에 영향을 주는 것을 확인하였다. 이 결과를 통해 유아의 문 제행동의 감소를 위해 어머니의 양육행동뿐 아니라 부모가 되 는 것의 의미와 가치를 비롯한 자녀가치에 대한 교육의 필요 성을 시사하며, 부모교육의 기초적 자료를 제공한다는 점에서 도 의의를 지닌다.

본 연구에서 얻어진 결과를 토대로 후속연구를 위한 제언 은 다음과 같다.

첫째, 어머니의 자녀가치와 더불어 아버지의 자녀가치에 대 한 연구가 요구된다. 자녀 양육을 어머니가 전임했던 과거와는 달리 양육에 참여하는 아버지가 늘어나고 있으며, 자녀의 사회 성 발달 등에 있어 아버지 양육참여가 영향을 미치는 것으로 보고되는 것들을 미루어 볼 때, 아버지의 자녀가치가 양육행동 과 자녀의 발달에 미치는 영향을 살펴볼 필요가 있다.

둘째, 자녀가치의 변화함에 따라 개인차가 존재하는 것을 확인하였다. 이는 자녀가치가 변화하는 것에 있어 개인차에 따른 유형에 대한 연구가 필요하다. 또한, 자녀가치에 영향을 주는 다양한 관련 변인을 찾는 연구가 필요하다. 예컨대, 정서 적 가치가 도구적 가치보다 더 변화폭이 큰 것은 부모가 되는 것에 대한 가치나 정서적 만족감을 의미하는 정서적 가치는 양육 스트레스나 부부갈등 등의 어머니가 받는 부정적인 정서 경험의 영향을 더 많이 받을 것으로 예상된다. 이에 자녀가치 에 영향을 주는 변인을 밝힐 필요가 있다.

\section{Notes}

This article is a part of the first author's master's thesis submitted in 2019. This article was presented at the 2018 Annal Spring Conference of the Korean Association of Child Studies. 


\section{Conflict of Interest}

No potential conflict of interest relevant to this article was reported.

\section{Ethics Statement}

All procedures of this research were reviewed by IRB (2018-06023).

\section{References}

\section{In English}

Arnold, F., \& Fawcett, J. T. (1986). The value of children : A crossnational study, Vol. 3: Hawaii. Honolulu, HI: University of Hawai'i Press.

Judith, G. S. (2017). Current research on parenting styles, dimensions, and beliefs. Current Opinion in Psychology, 15, 19-25. doi:10.1016/j.copsyc.2017.02.012

Leve, L. D., Kim, H. K., \& Pears, K. C. (2005). Childhood temperament and family environment as predictors of internalizing and externalizing trajectories from ages 5 to 17. Journal of Abnormal Child Psychology, 33(5), 505-520. doi:10.1007/s10802-005-6734-7

Okagaki, L., \& Sternberg, R. J. (1993). Parental beliefs and children's school performance. Child Development, 64(1), 36-56. doi:10.2307/1131436

Chan, S. M., Bowes, J., \& Wyver, S. (2009). Chinese parenting in Hong Kong: Links among goals, beliefs and styles. Early Child Development and Care, 179(7), 849-862. doi:10.1080/03004430701536525

Yoon, S., Yoon, D., Wang, X., Tebben, E., Lee, G., \& Pei, F. (2017). Co-development of internalizing and externalizing behavior problems during early childhood among child welfareinvolved children. Children and Youth Services Review, 82, 455-465. doi:10.1016/j.childyouth.2017.10.016

\section{In Korean}

Bae, B. R. (2011). Structural equation modeling with Amos 19: Principles and practice. Seoul: Chenglam.

Cho, B., Lee, J., Lee, H., \& Kwon, H. (1999). Dimensions and assessment of Korean parenting style. Family and Environment Research, 37(10), 123-133.
Kang, J. H., \& Oh, K. J. (2011). Gender differences in the effects of preschoolers' age, temperament and parenting for internalizing and externalizing problems. The Korean Journal of Women Psychology, 16(1), 1-21. doi:10.18205/ kpa.2011.16.1.001

Kim, M.-E. (2016). The effect of a child's temperament and a parent's rearing attitude on a child's problem behavior (Master's thesis). Retrieved from http://www.riss.kr/link?id= T14007253

Korea Institute of Child Care and Education. (2018). Panel study of korean children 1-3rd and 6th survey [Data file and code book]. Retrived from http://panel.kicce.re.kr

Kwon, Y. E. (2003). Similarities and differences of value of children across three generations: Comparative analysis adolescents, mothers, and grandmothers (Doctoral dissertation). Retrieved from http://www.riss.kr/link?id=T9985616

Lee, S.-J., \& Yoo, S.-O. (2012). An analysis of research trends and variables on children's challenging behaviors: Focusing on domestic articles. Early Childhood Education Research \& Review, 16(6), 127-156.

Lee, S., Jung, Y., Kim, H., Choi, E., Park, S., Jo, N., Sin, I.,... Kang, J. (2005). 2005 National survey on dynamics of marriage and fertility (Report No. 2005-30[1]). Seoul: Korean Institute for Health and Social Affairs.

Lee, J. A., Park, J. E., Chung, H. M., \& Yi, S. H. (2017). The structural analysis of parents' emotional value of children, parenting behavior, preschoolers' school readiness, and scholastic competence: The actor-partner interdependence model. Korean Journal of Early Childhood Education, 37(4), 453-477. doi:10.18023/kjece.2017.37.4.019

Lee, J., Kim, S., \& Lee, K. (2015). The developmental trajectory of the value of children of primiparous mothers during the first four years. Korean Journal of Child Studies, 36(4), $177-$ 192. doi:10.5723/KJCS.2015.36.4.177

Lim, H., \& Choi, S. (2015). The effects of child's temperament, child's language development and mothers' child value on positive and negative peer interactions. Korean Journal of Child Care and Education Policy, 9(1), 51-73.

Lim, S. A., \& Lim, H. J. (2015). Parenting-related factors influencing young children's problem behaviors: Focusing on the differences between employed and non-employed mothers. Korean Journal of Child Care and Education, 90, 159-184

Ok, K. (2018). The influence of children's values, parent-child interaction, and family cohesion and flexibility on paternal and maternal warmth and control parenting. Journal of Family Relations, 23(2), 47-65. doi:10.21321/jfr.23.2.47

Park, J.-H. (2012). Maternal value of children, parenting behavior, and infant development: Mediating effect of parenting behavior (Master's thesis). Retrieved from http://www.riss. 
$\mathrm{kr} / \mathrm{link}$ ?id=T12908940

Shin, K. N. (2016). The influence of the traits of a father with a toddler on the value of child and on parenting behavior (Master's thesis). Retrieved from http://www.riss.kr/ link?id=T13981670

\section{ORCID}

Hyun Soo Jung Jin Suk Lee
https://orcid.org/0000-0002-4653-672X

https://orcid.org/0000-0003-2681-0979

Received October 31, 2019

Revision received December 27, 2019

Accepted February 17, 2020 